\title{
Supervisão de agentes comunitários de saúde na Estratégia Saúde da Família: entre controle, apoio e formação
}

| ${ }^{1}$ Cristiane da Silva Marinho, ${ }^{2}$ José Patrício Bispo Júnior |

Resumo: O estudo objetivou analisar os mecanismos de supervisão do trabalho dos agentes comunitários de saúde na Saúde da Família e examinar como a supervisão exercida repercute na organização do trabalho. Trata-se de estudo qualitativo realizado em Vitória da Conquista, Bahia. Utilizou-se como referencial analítico uma matriz composta por três dimensóes: controle do trabalho, apoio ao trabalho e educação e formação. As informaçóes foram obtidas por meio de três grupos focais, 33 entrevistas semiestruturadas, observação direta e análise documental. Os participantes do estudo foram 42 agentes, oito supervisores e cinco gestores. Os resultados demonstraram o predomínio da supervisão como "controle do trabalho". Evidenciou-se uma perspectiva produtivista, com o controle das atividades desenvolvidas, especialmente as visitas domiciliares. Os mecanismos de avaliação exerceram forte influência nas práticas desenvolvidas. A dimensão "apoio" demostrou que o suporte dos supervisores contribui para o aprimoramento do trabalho, maior satisfação e respaldo social. A sobrecarga de atividades e o insuficiente apoio institucional influenciaram negativamente na supervisão de apoio. A dimensão "prática educativa" evidenciou processos formativos pontuais, instrumentais e direcionado para o controle de agravos. Conclui-se que é importante considerar, na supervisão, os aspectos políticos e socioculturais e buscar o equilíbrio entre essas três dimensóes.

> Palavras-chave: agente comunitário de saúde; supervisão; Saúde da Família; Atenção Básica; Sistema Único de Saúde.

\author{
1 Diretoria de Atenção Básica, \\ Prefeitura Municipal de Vitória da \\ Conquista. Vitória da Conquista- \\ BA, Brasil (cristianemarinho16@ \\ gmail.com). \\ ORCID: 0000-0002-6505-6115 \\ ${ }^{2}$ Instituto Multidisciplinar em \\ Saúde, Universidade Federal da \\ Bahia. Vitória da Conquista-BA, \\ Brasil (jpatricio@ufba.br). \\ ORCID: 0000-0003-4155-9612
}

Recebido em: 25/03/2020 Aprovado em: 05/08/2020 Revisado em: 16/09/2020 


\section{Introdução}

Os agentes comunitários de saúde (ACS) são considerados atores estratégicos para a superação dos modelos tradicionais de assistência e para o fortalecimento da atenção primária à saúde (RIQUINHO et al., 2018; ALONSO; BÉGUIN; DUARTE, 2018). No âmbito da Estratégia Saúde da Família (ESF), o trabalho do ACS é essencial para a territorialização, o diagnóstico dos problemas comunitários e o êxito das açóes desenvolvidas (FAUSTO et al., 2011).

Diversos autores (FAUSTO et al., 2011; SIMAS; PINTO, 2017; JUSTO; GOMES; SILVEIRA, 2015) destacam a peculiaridade de os agentes de saúde se constituírem como profissionais com dupla identidade: integrantes da comunidade e componentes das equipes de saúde. A atuação do ACS é fortemente marcada pelas atribuições de mediador entre interesses e necessidades da população e dos serviços de saúde (FAUSTO et al., 2011), cabendo articular as lógicas comunitária e institucional (RIQUINHO et al., 2018). Conforme destacam Justo, Gomes e Silveira (2015), as atribuiçóes dos ACS implicam a realização de tarefas que os expóem a situaçóes de conflito e que demandam esforços para conciliar perspectivas comunitária e científica e dar respostas às necessidades e problemas diversos.

Outra característica do trabalho dos agentes é a multiplicidade de atribuiçōes desenvolvidas. Alonso, Béguin e Duarte (2018) enfatizam que, além das atribuiçôes comunitárias, os ACS realizam grande elenco de tarefas que não lhes competem, como: trabalho na recepção, agendamento de consultas, controle de materiais e organização de almoxarifado, serviços de limpeza, dentre outros. Isso reforça a conformação do ACS como trabalhador genérico (MOROSINI; FONSECA, 2018), polivalente (ALONSO; BÉGUIN; DUARTE, 2018), que exerce uma função complexa (NOGUEIRA, 2019) e não claramente definida (RIQUINHO et al., 2018).

Diante desse cenário, cabe refletir sobre os aspectos que podem contribuir para a organização do trabalho do ACS e ampliar o desempenho das atribuiçóes, com melhores resultados para a população, o sistema de saúde e os próprios trabalhadores. De acordo com a literatura internacional, além dos fatores relacionados aos contextos econômico, político e comunitário (KOK et al., 2015a), a supervisão é apresentada como elemento capaz de influenciar positivamente no trabalho dos agentes, com a ampliação da motivação e do desempenho (KOK et al., 2015b). Conforme ressaltam 
Scott et al. (2018), a supervisão e o acompanhamento do trabalhador comunitário de saúde são elementos essenciais para o incremento da efetividade do sistema de saúde.

A partir da definição dos métodos avaliativos e das práticas que serão avaliadas, os trabalhadores tendem a direcionar o trabalho para o atendimento desses critérios (SCOTT et al., 2018). Dessa maneira, ao valorizar ou desvalorizar determinadas açôes, a metodologia de avaliação possui grande capacidade de influência sobre o processo de trabalho dos ACS (FONSECA et al., 2012). Fatores como a frequência e o local da supervisão, as relaçóes estabelecidas entre supervisores e agentes e as formas de supervisão estão entre os principais aspectos capazes de interferir no trabalho dos agentes de saúde (KOK et al., 2015b).

Com o fortalecimento do movimento dos cuidados primários em saúde, ampliouse a compreensão da necessidade de supervisionar os trabalhadores comunitários para vinculá-los ao sistema de saúde, prestar apoio ao desenvolvimento das atividades e possibilitar formação adequada (HILL et al., 2014). No contexto brasileiro, a Política Nacional de Atenção Básica (PNAB) estabelece a avaliação na ESF como responsabilidade de todas as esferas de governo e a institui como atribuição de todos os profissionais da equipe de Saúde da Família (eSF) (BRASIL, 2017). Isso se constitui em avanço para o aprimoramento dos serviços por possibilitar o deslocamento da avaliação dos gabinetes dos planejadores para o cotidiano dos trabalhadores da saúde (FONSECA; MENDONÇA, 2014).

Embora exista convergência sobre a importância da supervisão do ACS, há grande diversidade sobre o sentido atribuído e os modelos de supervisão. Na visão de Vasan et al. (2017), a supervisão é um processo em que profissionais especializados ou mais experientes prestam suporte para garantir o desempenho adequado do trabalho, além de envolver a orientação e apoio para melhorar a capacidade de atuação dos profissionais. Outra perspectiva considera a supervisão como integrante dos processos de avaliação em saúde, assumida como uma das tecnologias de gestão com maior capacidade de apoiar decisóes e apresentar os melhores resultados (FONSECA; MENDONÇA, 2014).

Estilos punitivos de supervisão têm sido desencorajados, por induzirem interaçóes negativas entre agentes e supervisores, o que pode desmotivar e criar obstáculos para o desenvolvimento do trabalho (SCOTT et al., 2018). Estudos internacionais (ASSEGAAI; SCHNEIDER, 2019) e nacionais (FONSECA; MENDONÇA, 2014; 
SILVA et al., 2014) apontam a necessidade de transformação da supervisão punitiva e burocrática para uma perspectiva de supervisão de apoio, na qual o estabelecimento de relaçôes horizontalizadas e o compartilhamento de responsabilidades teriam maior potência e efetividade no desempenho do trabalho dos agentes de saúde.

Frente a esse contexto, o estudo objetivou analisar os mecanismos de supervisão do trabalho dos agentes comunitários de saúde e examinar de que modo as práticas de supervisão repercutem na organização do trabalho do ACS no âmbito da Estratégia Saúde da Família.

\section{Métodos}

Trata-se de estudo de caso de abordagem qualitativa, desenvolvido no município de Vitória da Conquista, na regiâo Sudoeste da Bahia e com população de 346.069 habitantes (BRASIL, 2017). O município conta com 41 unidades de saúde de Atenção Primária, sendo 34 da Estratégia Saúde da Família e sete Unidades Básicas de Saúde tradicionais. Distribuídas nessas unidades, atuam 48 eSF, que garantem uma cobertura populacional de 48,87\%, e 11 equipes do Programa dos Agentes Comunitários de Saúde (PACS) (BRASIL, 2017). O campo foi constituído por seis Unidades de Saúde da Família (USF). As unidades participantes do estudo foram definidas aleatoriamente por meio de sorteio.

Para avaliar os mecanismos de supervisão e como eles influenciam o trabalho do ACS, foi desenvolvida uma matriz analítica fundamentada em três dimensôes: controle do trabalho, apoio ao trabalho e prática educativa e de formação (quadro 1). O desenvolvimento da matriz considerou os principais elementos presentes na literatura nacional e internacional que abordavam o processo de supervisão e como esta influencia na organização, motivação e desempenho do trabalho. De acordo com Kok et al. (2015a), a supervisão adequada dos trabalhadores comunitários de saúde deve envolver abordagens de apoio, solução de problemas, desenvolvimento pedagógico e acompanhamento e monitoramento das atividades desenvolvidas. 
Quadiro 1. Matriz de análise de supervisão de agentes comunitários de saúde

\begin{tabular}{|l|l|}
\hline \multicolumn{1}{|c|}{ Dimensão } & \multicolumn{1}{c|}{ Subdimensão } \\
\hline Controle do Trabalho & Mecanismos de supervisão \\
\cline { 2 - 3 } & Influência da supervisão sobre a organização de trabalho \\
\hline \multirow{4}{*}{ Apoio ao Trabalho } & Acolhimento de demandas e escuta \\
\cline { 2 - 3 } & Resolução de problemas \\
\cline { 2 - 3 } & Apoio à organização do trabalho \\
\cline { 2 - 2 } & Apoio da gestão local aos supervisores \\
\hline \multirow{3}{*}{ Prática educativa e de formação } & Modelos de formação instituídos \\
\cline { 2 - 3 } & Temas das atividades educativas \\
\cline { 2 - 2 } & Contribuições da educação para o trabalho \\
\hline
\end{tabular}

Fonte: elaboração própria.

A dimensão "controle do trabalho" refere-se à supervisão desempenhada com o intuito de monitorar o desempenho do trabalho do ACS (HILL et al., 2014). Nesta dimensão, os supervisores ajustam e direcionam a execução do trabalho aos padrôes e metas previamente definidas. Essa forma de supervisão é considerada tradicional e burocrática (HILL et al., 2014), embora não seja possível operar a supervisão dos trabalhadores de saúde sem certo grau de controle institucional (CECÍLIO, 1999).

A dimensão "apoio ao trabalho" envolve o diálogo entre supervisores e ACS para estabelecer objetivos claros, identificar e solucionar problemas, enfatizando a natureza colaborativa da supervisão, o planejamento conjunto das açóes e a busca de melhores resultados (ROBERTON et al., 2015). Essa concepção de supervisão contempla estratégias de comunicação, acolhimento às demandas, compartilhamento de responsabilidades e orientaçôes. A supervisão de apoio busca fortalecer as relaçôes entre ACS e supervisores, potencializando as relaçôes de confiança, a motivação e o desempenho do trabalho (KOK et al., 2018).

A dimensão educativa e de formação compreende a supervisão como suporte à qualificação humana e técnica para a formação pessoal e melhor desenvolvimento do trabalho (COMETTO et al., 2018; SCOTT et al., 2018). Pressupóe reflexão crítica de supervisores e ACS sobre a prática do trabalho, a fim de identificar necessidades sociais e promover a articulação entre conhecimentos teóricos e experiências empíricas (BARALDI, 2005). A supervisão enquanto dispositivo pedagógico deve promover 
a educação permanente dos trabalhadores, que envolve as orientaçôes cotidianas, cursos, capacitações e educação a partir da realidade vivenciada no território.

Realizou-se a triangulação de diferentes técnicas de coleta de dados: grupos focais, entrevistas semiestruturadas, observação participante e análise documental. A triangulação foi oportuna para potencializar a apreensão das diversas facetas da realidade (GIBBS, 2009). Os dados foram obtidos no período de fevereiro a maio de 2019.

Três grupos de participantes compuseram o estudo: agentes comunitários de saúde, enfermeiros/supervisores e gestores da atenção básica. Observaram-se os seguintes critérios de inclusão no estudo: possuir no mínimo um ano de experiência na profissão, ACS e supervisores com atuação em USF. Foram excluídos aqueles que, no momento da coleta de dados, encontravam-se afastados das atividades laborais.

Foram realizados três grupos focais (GF) com ACS e 33 entrevistas semiestruturadas (tabela 1). A mediaçáo dos GF foi realizada pela primeira autora do artigo com auxílio de uma relatora. A duração média dos grupos foi de uma hora. Os GF foram compostos por agentes de saúde pertencentes a pelo menos duas USF diferentes, a fim de promover a interação de diferentes experiências de supervisão vivenciadas. Entre os gestores, foram entrevistadas a diretora da atenção básica e quatro apoiadores institucionais. Os GF e as entrevistas foram guiados por roteiro com questôes que abordaram a identificação dos mecanismos adotados na supervisão e a influência dos mesmos na organização do trabalho do ACS. Os GF e entrevistas foram gravadas em aparelho de áudio digital e posteriormente transcritas.

Tabela 1. Técnicas de coleta e participantes do estudo. Vitória da Conquista-BA, 2019

\begin{tabular}{ccc}
\hline Técnicas de Coleta & Participantes & No de participantes \\
\hline Grupo Focal (GF) & ACS & 08 \\
GF1 & ACS & 08 \\
GF2 & ACS & 06 \\
GF3 & ACS & \\
Entrevistas Semiestruturada & Supervisores & 08 \\
& Gestores & 05 \\
\hline
\end{tabular}

Fonte: dados da pesquisa. 
As realidades observadas foram os encontros diários entre ACS e supervisores que acontecem no início do turno matutino, as reunióes semanais de equipe e as reunióes mensais de síntese e discussão do relatório de atividades (reunião de produtividade). Esses momentos foram considerados propícios para subsidiar a compreensão de aspectos relevantes da dinâmica de trabalho dos agentes. Nas reuniôes e encontros, buscou-se identificar: a presença de pautas e debates nas reuniôes de equipe relacionados ao trabalho dos ACS; a relação e a comunicação dos ACS com os supervisores e demais profissionais; a existência de práticas e mecanismos de avaliação e de controle do trabalho; e a presença de conflitos e busca de entendimentos. Utilizou-se diário de campo para registro das observações.

Para a análise documental, consideraram-se os seguintes elementos: Plano Municipal de Saúde (2014-2017), relatórios de gestão (2016 a 2018) e documentos do sindicato dos ACS, leis, portarias e resoluçóes referentes ao trabalho do ACS. Na análise, foram identificados o registro de normativas, regulamentaçóes e orientaçôes concernentes à organização ou controle das atividades desenvolvidas pelos agentes de saúde. Ao considerar que os documentos possuem a capacidade de explicitar os valores culturais e ideológicos que motivaram e determinaram sua produção, o conteúdo dos mesmos foi analisado e comparado com as informaçóes das outras fontes da pesquisa, a fim de identificar como as regulamentaçôes formais são incorporadas ao trabalho.

Foi utilizada a Técnica de Análise de Conteúdo temática para sistematização dos dados e informaçóes (GIBBS, 2009). Realizou-se inicialmente o processo denominado "codificaçáo aberta", que permite que os dados, ideias e eventos recebam um nome que os representem (STRAUSS; CORBIN, 2009). A partir do exame minucioso dos dados, procedeu-se à codificação axial, na qual esses códigos foram refinados, agrupados e integrados nas categorias (STRAUSS; CORBIN, 2009), para possibilitar sistematizaçôes relacionadas às dimensões da matriz de análise.

O estudo obedeceu a todas as recomendaçôes éticas e os participantes assinaram o Termo de Consentimento Livre e Esclarecido. O estudo foi aprovado pelo Comitê de Ética em Pesquisa (CEP) do Instituto Multidisciplinar em Saúde da Universidade Federal da Bahia, sob parecer n. 3.100.650. 


\section{Resultados}

Os resultados estão apresentados conforme as três dimensóes da matriz analítica. No quadro 2, estão dispostos os excertos das falas que ilustram as variáveis de cada dimensão.

Quadro 2. Resultados selecionados das subdimensões relacionadas à supervisão do trabalho dos agentes, segundo ACS, supervisores e gestores. Vitória da Conquista, 2019

\begin{tabular}{|c|c|c|}
\hline Dimensão & Variável & Excertos das falas \\
\hline \multirow[b]{2}{*}{$\begin{array}{l}\text { Controle } \\
\text { do trabalho }\end{array}$} & $\begin{array}{l}\text { Mecanismos } \\
\text { de supervisáo }\end{array}$ & $\begin{array}{l}\text { Na fich a eu tenho como ver se pelo menos as oito visitas por dia foram } \\
\text { realizadas, dificilmente eles passam dos oito né? Mas, é a forma que eu } \\
\text { tenho de fiscalizar a ação dos agentes na área. Uma vez por mês eu faço. } \\
\text { Essa é a minha forma de avaliação. (Supervisor 05) } \\
\text { A produtividade avalia mais os aspectos quantitativos. Infelizmente é } \\
\text { quantitativo, é tudo número, tudo número, número. (ACS 12) }\end{array}$ \\
\hline & $\begin{array}{l}\text { Influência da } \\
\text { supervisão } \\
\text { sobre a } \\
\text { organização } \\
\text { de trabalho }\end{array}$ & $\begin{array}{l}\text { Eu percebo que se eu cobrar eles fazem, se eu não cobrar eles não } \\
\text { fazem. Entäo, o enfermeiro tem um papel primordial na organização } \\
\text { do trabalho. Se você cobrar que eles façam, eles fazem, o que você não } \\
\text { cobrar, não faz, e aí fica bem desorganizado. (Supervisor 06) } \\
\text { Essa questão do monitoramento e avaliação é uma coisa fundamental } \\
\text { para gerar recurso, né? Se você não tá trabalhando, não tá gerando os } \\
\text { dados, o recurso não vem. Então, nossa cobrança, nossa supervisäo é } \\
\text { mais nesse sentido. (Gestor } 02 \text { ) }\end{array}$ \\
\hline \multirow{2}{*}{$\begin{array}{l}\text { Apoio ao } \\
\text { trabalho }\end{array}$} & $\begin{array}{l}\text { Acolhimento } \\
\text { de demandas } \\
\text { e escuta }\end{array}$ & $\begin{array}{l}\text { Quando a gente não consegue a gente passa pra enfermeira, né? A gente } \\
\text { tem um tempinho pela manhã pra se reunir com ela. (ACS 15) } \\
\text { Às vezes, a gente tá na área e surge alguma demanda, até na hora ali a } \\
\text { gente manda um zap pra enfermeira, ela responde de imediato. Ai tem } \\
\text { essa facilidade, união e comunicação boa. (ACS 18) }\end{array}$ \\
\hline & $\begin{array}{l}\text { Resolução de } \\
\text { problemas }\end{array}$ & $\begin{array}{l}\text { Tem casos que não é da nossa responsabilidade que o agente não } \\
\text { consegue resolver sozinho, porque depende da enfermeira, e aí tem essa } \\
\text { ligação, é gostosa essa ligação, esse ir e trazer, né? (ACS 06) } \\
\text { Porque a gente sai do posto pra ir até o paciente, você traz uma } \\
\text { demanda, então chega aqui você tem que ter alguém pra te apoiar, pra } \\
\text { te ajudar, pra te orientar pra você levar uma resposta (ACS 15) }\end{array}$ \\
\hline
\end{tabular}

continua... 


\begin{tabular}{|c|c|c|}
\hline Dimensão & Variável & Excertos das falas \\
\hline \multirow[t]{2}{*}{$\begin{array}{l}\text { Apoio ao } \\
\text { trabalho }\end{array}$} & $\begin{array}{l}\text { Apoio à } \\
\text { organização } \\
\text { do trabalho }\end{array}$ & $\begin{array}{l}\text { Antes deles saírem pra área a gente tá coordenando, orientando as } \\
\text { demandas do próprio serviço, eles colocam as dificuldades deles, então a } \\
\text { gente tá sempre orientando. (Supervisor 02) } \\
\text { A enfermeira não consegue mais ter pernas pra essa supervisão da forma } \\
\text { que que deveria ser. Aquela supervisáo diária que deveria acontecer, } \\
\text { ela já náo acontece mais devido à demanda. A gente precisa priorizar } \\
\text { outras coisas e acaba näo conseguindo. (ACS 16) }\end{array}$ \\
\hline & $\begin{array}{l}\text { Apoio da } \\
\text { gestão } \\
\text { municipal aos } \\
\text { supervisores }\end{array}$ & $\begin{array}{l}\text { Hoje tem mil coordenadoras, tem uma apoiadora, mas que não apoia } \\
\text { nada. Na maioria das vezes, não apoia nada. Aqui, atualmente, eu } \\
\text { nem sei quem é a apoiadora, não conheço. (Grupo Focal 03) } \\
\text { A supervisão direta é das enfermeiras lá, eu como apoiadora, minha } \\
\text { postura é não interferir muito nisso daí. (Gestor 04) }\end{array}$ \\
\hline \multirow{3}{*}{$\begin{array}{l}\text { Prática } \\
\text { educativa } \\
\text { e de } \\
\text { formação }\end{array}$} & $\begin{array}{l}\text { Modelos de } \\
\text { formação } \\
\text { instituídos }\end{array}$ & $\begin{array}{l}\text { O processo de formação e capacitação ainda é deficiente. Mas, eu ainda } \\
\text { faço quando eu percebo alguma demanda na área ou que chega aqui } \\
\text { pra gente, eu geralmente faço alguma atividade educativa na própria } \\
\text { reunião. Mas, eu considero isso uma deficiência. Por mais que eu faça, } \\
\text { ainda é pontual, não é uma coisa rotineira, de fazer uma vez por mês, } \\
\text { não é. (Supervisor 08) } \\
\text { Eu acho que precisa sim que o polo [de educação permanente] entre } \\
\text { nessas questöes de capacitação permanente mesmo. Que seja aquela } \\
\text { coisa, não coisa pontual, coisa pontual acaba. (Gestor 02) }\end{array}$ \\
\hline & $\begin{array}{l}\text { Temas das } \\
\text { atividades } \\
\text { educativas }\end{array}$ & $\begin{array}{l}\text { Säo muitas doenças, né? Ai quando vem as sazonais a gente chama } \\
\text { atenção pra o Sarampo, pra Dengue... tá sempre batendo nesta tecla. } \\
\text { (Supervisor 02) } \\
\text { Esse curso que a gente começou, disseram que iria ser dois ou três módulos } \\
\text { e a gente só fez um módulo. Foi extremamente positivo, foi muito bom, só } \\
\text { que eles começaram e deixaram no meio do caminho. (Grupo Focal 02) } \\
\text { Falta também por parte do apoio institucional questöes de formação para } \\
\text { o agente comunitário relacionados ao seu processo de trabalho e náo só } \\
\text { questōes da vigilância epidemiológica, pra se tratar de tuberculose. Mas } \\
\text { questöes do processo de trabalho do ACS. (Supervisor 08) }\end{array}$ \\
\hline & $\begin{array}{l}\text { Contribuições } \\
\text { da educação } \\
\text { para o } \\
\text { trabalho }\end{array}$ & $\begin{array}{l}\text { Como é um grupo que trabalha com muita gente sempre surge dúvidas, } \\
\text { então a gente tem que chamar, puxar pro foco, pra o que realmente é } \\
\text { importante. (Supervisor 02) } \\
\text { A enfermeira gosta de tá deixando a gente atualizado, ela fez um } \\
\text { curso, uma capacitação no dia de reunião e empoderou a gente mais da } \\
\text { vacina. (ACS 08) }\end{array}$ \\
\hline
\end{tabular}

Fonte: elaboração própria. 


\section{Controle do trabalho}

Os resultados evidenciaram a predominância da supervisão enquanto controle e fiscalização do trabalho dos ACS. Assim, a supervisão apresentou forte componente de acompanhamento e monitoramento da rotina do trabalho dos agentes. Foram destacados o sentido normatizador de fiscalização da frequência e turnos de trabalho. Além disso, a produtividade das açôes desenvolvidas pelos agentes figurou como principal elemento utilizado para a avaliação do trabalho. Esses mecanismos foram associados a um modelo de supervisão burocratizado, focado em açóes programáticas e muitas vezes não correspondentes às necessidades sociais dos territórios.

Sobre os mecanismos utilizados, identificaram-se como principais açôes desenvolvidas: encontros diários entre supervisores e ACS no início do turno matutino, reunião mensal de produtividade, visita domiciliar de supervisão e feedback dos usuários. Nos encontros diários, são desenvolvidas ações das três dimensões analisadas. No que tange à dimensão controle, observou-se que nesses momentos predominam demandas burocráticas como monitoramento da frequência e da pontualidade e repasse de informaçóes.

A reunião da produtividade foi referida como principal mecanismo de avaliaçáo, com foco na prestação de contas do trabalho executado. Essa avaliação é desenvolvida a partir da quantificação das açóes realizadas, tais como número de famílias cadastradas e visitadas, dados coletados por grupos populacionais específicos e controle diário de visitas realizadas. Conforme destacado pelo supervisor 5 (quadro 2), a avaliação se restringiu ao controle da realização de oito visitas domiciliares diárias por agente. Esse modelo voltado apenas ao controle de atividades mostrou desconsiderar as especificidades do trabalho comunitário. Assim, as atividades comunitárias, intersetoriais e de participação social ocuparam restrito espaço nos momentos de avaliaçáo da produtividade do ACS.

A organização do trabalho do agente comunitário se mostrou fortemente influenciada pelos mecanismos de supervisão. Foi evidenciada a existência de um modelo de cobrança indutor de produtividade, sendo relatado que, quando ocorrem falhas na cobrança pelos supervisores, há impactos negativos no trabalho desempenhado pelo agente (quadro 2, supervisor 6).

Dentre as atividades desempenhadas pelos ACS, a visita domiciliar foi identificada como a mais valorizada no processo de supervisão. Em decorrência, estas assumiram centralidade no fazer cotidiano dos agentes. Apesar da importância 
dessa atividade, a valorização foi reduzida essencialmente às questôes numéricas de realização do número de visitas estabelecido pela Secretaria Municipal de Saúde. Os instrumentos e práticas de controle não contemplavam a subjetividade que reveste a visita domiciliar e todos os desdobramentos que, por vezes, transcendem os objetivos iniciais da mesma.

O modelo produtivista também foi relacionado à reprodução do sentido de avaliação exercida pelos gestores municipais sobre o supervisor. Preponderou entre os gestores a perspectiva da avaliação como ferramenta para potencializar a alimentação dos sistemas de informação e, consequentemente, a captação de recursos financeiros. A fala do gestor 2 (quadro 2) ilustra o entendimento do controle de metas com a finalidade da garantia do financiamento. Desse modo, o formato da supervisão dos agentes mostrou-se influenciado pelos interesses e parâmetros, especialmente relativos às visitas domiciliares, pactuados em outros níveis do sistema.

\section{Apoio ao trabalho}

Foi possível identificar, no processo de supervisão, açôes de suporte dos enfermeiros para o trabalho do ACS. O apoio do supervisor foi relacionado ao aprimoramento e melhor desempenho das funçóes exercidas pelos agentes, a ampliação da satisfação com o trabalho, assim como importante recurso para consolidar a credibilidade junto à comunidade.

Os agentes de saúde demonstraram sentirem-se apoiados no acolhimento de suas demandas. Cotidianamente, são identificadas situaçôes nos territórios sobre as quais os agentes demonstraram necessitar de suporte para a resolução ou os encaminhamentos. Nesse sentido, os resultados demonstraram que o supervisor constitui-se como principal referência do ACS para a escuta dos problemas, as orientaçôes sobre as ações a serem desenvolvidas e a busca compartilhada de soluçôes. Um importante aspecto foi a facilidade de acesso aos supervisores e a disponibilidade destes para escuta dos agentes, como evidenciam as entrevistas 15 e 18 dos ACS (quadro 2).

Apesar da relevância da supervisão de apoio, também foram evidenciados entraves e dificuldades para que o apoio pudesse ser desenvolvido em maior potência. Os encontros diários entre ACS e supervisores eram pouco explorados para promover mudanças no processo de trabalho. No período de observaçôes, identificou-se que frequentemente, quando os supervisores chegavam à unidade, alguns ACS já 
haviam saído para a área ou estavam em outro setor da unidade resolvendo outras demandas, o que limitou a utilização dessas oportunidades para discussão de questôes relacionadas à organização do trabalho.

Também a sobrecarga de trabalho nas unidades de saúde e os múltiplos papéis atribuídos aos enfermeiros implicaram menor tempo dedicados ao exercício de supervisão de apoio. A entrevista do ACS 16 (quadro 2) revela a fragilidade do apoio prestado em decorrência da elevada demanda de responsabilidades dos enfermeiros nas eSF. Neste sentido, a supervisão de apoio aos ACS mostrou-se afetada e secundarizada. Foi constatado ainda que o suporte ofertado ao ACS possuía resolutividade restrita, pois muitas demandas relacionavam-se a problemas sociais e estruturais, ou dependiam de ações de níveis hierárquicos superiores do sistema de saúde.

Sobre o suporte da gestáo municipal à atividade de supervisão, os resultados demonstraram que os supervisores recebiam apoio insuficiente da gestão municipal para o desenvolvimento da funçáo. Foram identificadas irregularidades no fluxo de comunicação e inexistência de agenda de encontros entre os apoiadores institucionais e os supervisores, evidenciando fragilidades do apoio institucional. Os próprios gestores relataram não se sentir responsáveis e mantêm postura de distanciamento da supervisão e não acompanhamento do trabalho dos enfermeiros, consoante fala do gestor 4 (quadro 2). Mesmo em situaçóes de desvio de conduta e posturas incongruentes por parte dos agentes, os supervisores demonstraram não encontrar respaldo junto aos gestores para a resolução do problema.

\section{Prática educativa e de formação}

O estudo mostrou que a supervisão também está ligada à perspectiva educativa. Foi identificado que os ACS recorrem aos supervisores para obter informaçóes e conhecimentos que subsidiem a resolução dos problemas demandados das comunidades. Em contrapartida, os supervisores valorizaram o conhecimento ampliado e singular que os ACS possuem sobre os condicionantes sociais do território como subsídio para a atuação da equipe.

No cotidiano do trabalho, constatou-se que as açôes de supervisão no sentido pedagógico e formativo não foram instituídas de forma sistematizada e em caráter permanente. Essas transcorreram de maneira pontual e esporádica. Conforme ressalta a entrevista do supervisor 8 (quadro 2), o processo de formação é insuficiente 
e inadequado para as peculiaridades do trabalho dos agentes. De acordo com a fala do gestor 2, o modelo de formação instituído deve superar o caráter fortuito e ser assumido pelo núcleo de educação da Secretaria de Saúde. Assim, evidenciou-se a necessidade de organizar uma política de educação permanente, uma vez que os ACS devem exercer atribuiçôes ancoradas principalmente à dimensão educativa.

As atividades educativas ocorrem em resposta à identificação de problemas pelo ACS ou para atender a demandas da gestão em ocasióes de surtos ou epidemias. Assim, os conteúdos assumem caráter técnico, voltados para as capacitaçóes sobre habilidades clínicas e assistenciais, com temáticas focadas nas doenças crônicas e transmissíveis. Além da abordagem eventual e fragmentada, a formação esteve centrada nos aspectos biológicos de controle de doenças e açóes de vigilância epidemiológica em âmbito comunitário. Evidenciou-se a carência de processos formativos que contemplem os aspectos políticos e socioculturais do trabalho, o que é evidenciado na entrevista do supervisor 8 (quadro 2). A formação relacionada às atribuiçôes comunitárias, sociais e políticas mostrou-se quase inexistente. Raramente as ações de qualificação profissional oportunizaram o debate sobre o processo de trabalho e sobre as diversas situações relacionadas a dinamicidade e singularidade do trabalho social e comunitário.

O curso técnico em agentes comunitários, iniciado em 2010 no município, foi identificado como estratégia pedagógica importante no processo de formação desses trabalhadores. A importância e necessidade do curso técnico para os ACS foram discutidas no grupo focal 2 (quadro 2). Embora o município tenha ofertado apenas o primeiro módulo, os agentes ressaltaram a aprendizagem possibilitada pela discussão e problematização da prática do trabalho, visto que o curso contemplava a articulação dos fundamentos teóricos com as vivências cotidianas nas comunidades.

Os gestores ressaltaram a importância do caráter educativo da supervisão e reconheceram que esta também é uma atribuição do apoio institucional. Todavia, referiram que os supervisores pelo contato mais próximo com os agentes conseguem identificar melhor as necessidades que devem ser abordadas no cotidiano de trabalho.

Mesmo diante de limitaçôes, a supervisão enquanto suporte educativo mostrou-se associada a um melhor desempenho dos trabalhadores comunitários. As capacitaçôes e especialmente os treinamentos práticos, com foco nas peculiaridades do trabalho comunitário, implicaram melhor desenvolvimento profissional. 


\section{Discussão}

As atividades de supervisão do trabalho do ACS identificadas no estudo englobaram as três dimensôes da matriz de análise. A supervisão desenvolvida se mostrou como atividade de monitoramento e controle do trabalho dos agentes, como prática de apoio para a resolução de problemas e como meio de educação e formação dos ACS. Mesmo contemplando as três dimensóes, observou-se o predomínio das atividades pautadas no controle e na fiscalizaçáo do trabalho. As atividades de apoio e de formação, capazes de qualificar o trabalho e ampliar o desempenho dos agentes na função comunitária, mostraram-se preteridas diante da avaliação de controle.

De modo similar, estudos sobre a supervisão de trabalhadores comunitários no Brasil (SILVA et al., 2014; ALONSO; BÉGUIN; DUARTE, 2018) e no cenário internacional (ROBERTON et al., 2015; RODRÍGUEZ; PETERSON, 2016) demonstram que a supervisão se concentra principalmente na prestação de contas das atividades desenvolvidas e na checagem de relatórios e registros. Embora se reconheça a avaliação como importante atividade dos sistemas de saúde, observa-se o predomínio de práticas de avaliação focadas no monitoramento, que contribui de forma restrita para o aprimoramento do trabalho do ACS (FONSECA; MENDONÇA, 2014). Nesta perspectiva, os critérios técnicos de planejamento e de avaliação, bem como os instrumentos de registro das atividades, estão vinculados à estrutura de controle do trabalho fortemente arraigada na racionalidade instrumental (JUSTO; GOMES; SILVEIRA, 2015).

Conforme evidenciado nos resultados, a perspectiva quantitativa revelou-se hegemônica no processo de supervisão. A produtividade mensal assumiu centralidade como critério avaliativo do trabalho dos agentes. Importante ressaltar que a cobrança aos agentes para o cumprimento de determinado número de açóes é o desdobramento da cobrança feita aos supervisores para a manutenção da produtividade da equipe. De maneira similar, Silva et al. (2014) identificaram que o trabalho da supervisão do ACS é guiado muitas vezes pela finalidade de fazer o agente cumprir uma meta numérica de açóes definidas pelos gestores alheios às realidades dos serviços.

Nas práticas de avaliação desempenhadas, predominou a perspectiva da produção de dados, com incipiente reflexão crítica sobre os aspectos subjetivos que permeiam a complexidade do trabalho executado pelos agentes. Dessa forma, determinadas situações que não se inserem nas características do campo biológico e nas orientaçôes técnicas sobre os agravos foram pouco valorizadas no conjunto da avaliação. 
A importância conferida aos instrumentos de supervisão, como as fichas de consolidação da produtividade, o registro de assinaturas e outros desenvolvidos pelos próprios supervisores, além de restringirem a discussão para o conteúdo solicitado nos instrumentos, interferiu na organização do trabalho do ACS. Conforme evidenciado, ocorreu a focalização prioritária do cumprimento burocrático das açôes cobradas e a secundarização da abordagem sobre as condições de vida, finalidade precípua do trabalho.

Justo, Gomes e Silveira (2015) apontam existir a transfiguração da finalidade do trabalho em recursos técnicos de mensuração. As atividades dos agentes, especialmente as visitas domiciliares, que têm o propósito de promover o cuidado das comunidades, passam a constituir uma finalidade em si mesma, com repercussóes negativas na qualidade do trabalho. Ao direcionar as práticas a partir do enfoque produtivista, os processos avaliativos reforçam e direcionam o trabalho para o modelo centrado na doença e em açóes programáticas ou emergenciais, o que se mostra contraditório com a reorientação atribuída à ESF (MOROSINI; FONSECA, 2018; NOGUEIRA, 2019).

Outro ponto de reflexão são as contradições da própria PNAB (BRASIL, 2017) sobre os mecanismos avaliativos. Sobre isso, Morosini e Fonseca (2017) ressaltam que no texto da política é anunciado que a avaliação não deve ter caráter prescritivo, todavia também na política se preconiza a possibilidade de remuneração adicional com base em avaliação de desempenho.

Os aspectos de apoio ao trabalho se expressaram pelo acolhimento das demandas, suporte e orientaçôes de como proceder frente aos problemase construção compartilhada de alternativas. Essas características revelam aspectos positivos da supervisão capazes de influenciar no desempenho das atividades e exercer motivaçáo para o agente. Por se sentirem apoiados, os ACS ampliam o vínculo e a confiança com os supervisores, o que também lhes concede maior respaldo para a atuação na comunidade.

A supervisão de apoio ganha ainda mais relevância frente a complexidade do trabalho e grande abrangência de atribuiçóes do agente de saúde. Em estudo de revisão sistemática (ALONSO; BÉGUIN; DUARTE, 2018), identificou-se a falta de dimensionamento do trabalho do agente, com pouca clareza de suas atribuiçóes. Esse quadro reforça a concepção do ACS como um trabalhador polivalente, com o escopo de atuação constantemente alargado (ALONSO; BÉGUIN; DUARTE, 2018). 
Assim, o suporte desenvolvido pelo supervisor assume características de retaguarda, para lhe conferir suporte técnico ao trabalho e respaldo social junto à comunidade.

$\mathrm{Na}$ literatura internacional, a supervisão de apoio é amplamente difundida como importante elemento para ampliar a motivação e o desempenho dos trabalhadores comunitários de saúde (COMETTO et al., 2018). Em estudo de intervenção sobre os modelos de supervisão desenvolvido em quatro países africanos identificou-se que a mudança da supervisão de uma perspectiva "de caça aos erros" para "busca se solução de problemas" trouxe resultados significativos sobre a motivação e o desempenho dos agentes (KOK et al., 2018).

Apesar dos potenciais identificados, o presente estudo também revelou dificuldades para a operacionalização da supervisão de apoio. As fragilidades das reunióes entre ACS e supervisores, a sobrecarga de trabalho dos enfermeiros e os graves problemas sociais e estruturais dos territórios apresentaram-se como limitadores do apoio. Segundo Fausto et al. (2011), as áreas de atuação dos agentes de saúde, em grande medida, são em territórios de grande exclusão social e com populaçôes expostas a condiçôes de vida e saúde degradantes. Assim, a solução dos problemas perpassa necessária atuação sobre os determinantes sociais da saúde.

Outro achado relevante foi o insuficiente suporte prestado aos supervisores por parte da gestão municipal. Esse resultado expressa que o desenvolvimento da supervisão de apoio não está restrito às relaçóes internas das eSF ou ao modelo de conduta do supervisor, mas é também determinado pelo nível de envolvimento e comprometimento do nível central da gestâo em saúde.

Sobre a dimensão educativa, o encontro frequente entre supervisores e ACS e as iniciativas dos supervisores em qualificar e informar os agentes favoreceu o estabelecimento da prática formativa no processo de supervisão. No entanto, os achados também indicaram limitaçôes na formação desenvolvida e ausência de uma política de educação permanente destinada aos agentes.

A supervisão foi identificada como potencial estratégia pedagógica para a qualificação do processo de trabalho. Todavia, os elementos formativos da supervisão mencionados no estudo foram voltados à eventuais problemas identificados pelos agentes no cotidiano de trabalho ou decorrentes do contexto epidemiológico momentâneo. Para o atendimento dessas demandas, predominaram cursos esporádicos, com abordagem biológica e incipiente abordagem sobre complexidade e subjetividade das práticas. Neste sentido, o cenário estudado 
revela inadequaçóes tanto relacionadas à abordagem ampliada de saúde quanto ao modelo de formação dos profissionais.

Capacitaçôes pontuais e fragilidades na educação permanente no âmbito da Saúde da Família também foram reveladas em outros cenários (BARRETO et al., 2018; BISPO JÚNIOR; MOREIRA, 2017). De acordo com Barreto et al. (2018), a formação profissional insuficiente é fator de estresse e de insegurança dos agentes de saúde. A complexidade do trabalho dos ACS e o contato com problemas diversos exigem um processo de educação permanente que não foi assumido integralmente pelas esferas de gestão do SUS (SIMAS; PINTO, 2017). No contexto estudado, isso pode ser exemplificado pela transferência da responsabilidade para os supervisores e pela oferta apenas do primeiro módulo do curso técnico para ACS, que está inconcluso há quase dez anos.

Outro ponto de destaque foi a ausência de formação sobre a dimensão comunitária e emancipadora do trabalho do ACS. De acordo com Pereira e colaboradores (PEREIRA et al., 2016), historicamente a concepção pedagógica que fundamenta a formação dos agentes é a pedagogia das competências, que ratifica o conhecimento com base em seu caráter instrumental. Para os autores, quando o processo ensinoaprendizagem é orientado por essa concepção, ganha caráter utilitarista focado em questóes pontuais e com baixa capacidade de desenvolvimento dos sujeitos. Para Nogueira (2019), a formação dos ACS segue aligeirada e inespecífica, com repercussôes sobre o desenvolvimento do trabalho e a identidade profissional. Assim, parece ir se conformando um processo de inter-relação e potencialização entre a conformação do trabalho focado na multiplicidade de atribuiçôes simplificadas e um processo formativo instrumental e voltado para o controle de doenças. Como consequência, o trabalho do agente se distancia do caráter comunitário e é aprisionado pela racionalidade biomédica, com consequente desqualificação e alienação dos processos formativos.

O estudo revelou que o tipo de supervisão exercida influencia diretamente na forma de organização do trabalho. Dessa maneira, o predomínio do mecanismo de supervisão pautado numa perspectiva normatizadora e burocrática implicou o redirecionamento das práticas do ACS para as atividades quantificáveis em detrimento da atuação de mobilização comunitária, educativa e com abordagem intersetorial.

É possível concluir que a confluência entre as três dimensóes analisadas potencializa o trabalho do ACS e contribui para relaçôes mais horizontalizadas e 
resolutivas na Saúde da Família. Face a tal constatação, é imprescindível rever o exercício da supervisão de maneira que contemple as peculiaridades do trabalho e que direcione os ACS para assumir o protagonismo da atuação sobre as condiçôes de vida nos territórios. ${ }^{1}$

\section{Referências}

ALONSO, C. M.; BÉGUIN, P. D.; DUARTE, F. J. Trabalho dos agentes comunitários de saúde na Estratégia Saúde da Família: metassíntese. Revista de Saúde Publica, São Paulo, v. 52, p. $14,2018$.

ASSEGAAI, T.; SCHNEIDER, H. National guidance and district-level practices in the supervision of community health workers in South Africa: a qualitative study. Human Resources for Health, Londres, v. 17, n. 1, p. 25, 2019.

BARALDI, S. Supervisão, flexibilização e desregulamentação no mercado de trabalho: antigos modos de controle, novas incertezas nos vínculos de trabalho da enfermagem. 2005. (Tese de Doutorado). Escola de Enfermagem, Universidade de São Paulo, São Paulo, 2005.

BARRETO, I. C. et al. Complexidade e potencialidade do trabalho dos Agentes Comunitários de Saúde no Brasil contemporâneo. Saúde em Debate, Rio de Janeiro, v. 42, n. esp 1, p. 114-129, 2018. BISPO JÚNIOR, J. P.; MOREIRA, D. C. Educação permanente e apoio matricial: formação, vivências e práticas dos profissionais dos Núcleos de Apoio à Saúde da Família e das equipes apoiadas. Cadernos de Saúde Pública, Rio de Janeiro, v. 33, n. 9, e00108116, 2017.

BRASIL. Ministério da Saúde. Portaria n. 2436, de 21 de setembro de 2017. Aprova a Política Nacional de Atenção Básica, estabelecendo a revisão de diretrizes para a organização da Atenção Básica, no âmbito do Sistema Único de Saúde (SUS). Diário Oficial da União. Brasília-DF, 21 set. 2017.

Ministério da Saúde. SAGE. Sala de Apoio à Gestão Estratégica. Redes e Programas. Saúde mais perto de você: Atenção Básica. 2017. Disponível em http://sage.saude.gov.br/\# ; Acesso em: 2 mar 2020.

CECÍLIO, L. C. Autonomia versus controle dos trabalhadores: a gestão do poder no hospital. Ciência \& Saúde Coletiva. Rio de Janeiro, v. 4, n. 2, p. 315-329, 1999.

COMETTO, G. et al .Health policy and system support to optimise community health worker programmes: an abridged WHO guideline. The Lancet Global Health, Londres, v. 6, n. 12, p. e1397-e1404, 2018.

FAUSTO, M. C. et al. The Work of Community Health Workers in Major Cities in Brazil: Mediation, Community Action, and Health Care. The Journal of Ambulatory Care Management, Filadélfia, v. 34, n. 4, p. 339-353, 2011. 
FONSECA, A. F. et al. Avaliação em saúde e repercussões no trabalho do agente comunitário de saúde. Texto \& Contexto - Enfermagem, Florianópolis, v. 21, n. 3, p. 519-527, 2012.

FONSECA, A. F.; MENDONÇA, M. H. A interação entre avaliação e a atuação dos Agentes Comunitários de Saúde: subsídios para pensar sobre o trabalho educativo. Saúde em Debate, Rio de Janeiro, v. 38, n. esp, p. 343-357, 2014.

GIBBS, G. Análise de dados qualitativos. Porto Alegre: Artmed, 2009.

HILL, Z. et al. Supervising community health workers in low-income countries--a review of impact and implementation issues. Global health action, Umea,v. 7, n. 7, p. 24085, 2014.

JUSTO, C. L. M. P.; GOMES, M. H. D.; SILVEIRA, C. S. Limites e imposiçóes dos instrumentos de controle do trabalho de agentes comunitários de saúde da Estratégia Saúde da Família. Saúde e Sociedade, São Paulo, v. 24, n. 2, p. 594-606, 2015.

KOK, M. C. et al. A qualitative assessment of health extension workers' relationships with the community and health sector in Ethiopia: opportunities for enhancing maternal health performance. Human resources for health, Londres,v. 30, n. 13, p. 80, 2015 a.

KOK, M. C. et al. Does supportive supervision enhance community health worker motivation? A mixed-methods study in four African countries. Health policy and planning, Londres,v. 33, n. 9, p. 988-998, 2018.

KOK, M. C. et al. Which intervention design factors influence performance of community health workers in low- and middle-income countries? A systematic review. Health policy and planning, Londres, v. 30, n. 9, p. 1207-1227, 2015 b.

MOROSINI, M. V.; FONSECA, A. F. Os agentes comunitários na Atenção Primária à Saúde no Brasil: inventário de conquistas e desafios. Saúde em Debate, Rio de Janeiro, v. 42, n. esp 1, p. 261-274, 2018.

. Revisão da Política Nacional de Atenção Básica numa hora dessas? Cadernos de Saúde Pública, Rio de Janeiro, v. 33, n. 1, e00206316, 2017.

NOGUEIRA, M. L. Expressóes da precarização no trabalho do agente comunitário de saúde: burocratização e estranhamento do trabalho. Saúde e Sociedade, São Paulo, v. 28, n. 3, p. 309-323, 2019.

PEREIRA, I. D. et al. Princípios pedagógicos e relaçóes entre teoria e prática na formação de agentes comunitários de saúde. Trabalho, Educação e Saúde, Rio de Janeiro, v. 14, n. 2, p. 377-397, 2016.

RIQUINHO, D. L. et al. O cotidiano de trabalho do Agente Comunitário de Saúde: entre a dificuldade e a potência. Trabalho, Educação e Saúde, Rio de Janeiro, v. 16, n. 1, p. 163-182, 2018. ROBERTON, T. et al. Initial experiences and innovations in supervising community health workers for maternal, newborn, and child health in Morogoro region, Tanzania. Human Resources for Health, Londres, v. 13, n. 1, 19, 2015. 
RODRÍGUEZ, D. C.; PETERSON, L. A. A retrospective review of the Honduras AIN-C program guided by a community health worker performance logic model. Human Resources for Health, v. 14, n. 1, 19, 2016.

SCOTT, K. et al. What do we know about community-based health worker programs? A systematic review of existing reviews on community health workers. Human Resources for Health, Londres, v. 16, n. 1, 39, 2018.

SILVA, J. S. D. et al. Supervisão dos Agentes Comunitários de Saúde na Estratégia Saúde da Família: a ótica dos enfermeiros. Revista da Escola de Enfermagem da USP, São Paulo, v. 48, n. 5, p. 899-906, 2014.

SIMAS, P. R. P.; PINTO, I. C. D. M. Trabalho em saúde: retrato dos agentes comunitários de saúde da regiāo Nordeste do Brasil. Ciência \& Saúde Coletiva, Rio de Janeiro, v. 22, n. 6, p. 1865-1876, 2017.

STRAUSS, A.; CORBIN, J. Pesquisa qualitativa: técnicas e procedimentos para o desenvolvimento de teoria fundamentada. 2 ed. Porto Alegre: Artmed, 2009.

VASAN, A. et al. Support and performance improvement for primary health care workers in low- and middle-income countries: a scoping review of intervention design and methods. Health policy and planning, Londres, v. 32, n. 3, p. 437-452, 2017.

\section{Nota}

${ }^{1}$ C. da S. Marinho contribuiu na concepção do estudo, planejamento, coleta de dados, análise e interpretação dos dados, redação do manuscrito e aprovação da versão final. J. P. Bispo Júnior contribuiu na concepção do estudo, planejamento, análise e interpretação dos dados, redação do manuscrito e aprovação da versão final. 


\section{Abstract}

Supervision of Community Health Worker in the Family Health Strategy: among control, support and training

The study aimed to analyze the supervision mechanisms regarding the work of Family Health community health workers (CHW) and how the practiced supervision affects the work organization. This is a qualitative study carried out in Vitória da Conquista, state of Bahia, Brazil. In the analytical referential, a matrix comprised three dimensions: work control, work support, education and training. Information was collected through three focus groups, 33 semi-structured interviews, direct observation, and document analysis. Study participants were $42 \mathrm{CHW}$, eight supervisors and five managers. The outcomes showed predominance of supervision as work control. A productive approach was noticed with the control of the developed activities, particularly home visits. Assessment mechanisms displayed a strong influence on the developed practices. The support dimension demonstrated that the supervisors support foment work performance, higher satisfaction and social support. Activity overcharge and the deficient institutional support negatively affected supportive supervision. The practical educational dimension displayed punctual and instrumental formative process directed to diseases control. We concluded that it is essential to take into account in the supervision the political and sociocultural aspects and pursue the balance among the three dimensions.

Keywords: community health worker; supervision; Family Health; Primary Health Care; Unified Health System. 